\title{
Retraction Note to: Archaeal amoA Genes Outnumber Bacterial amo $A$ Genes in Municipal Wastewater Treatment Plants in Bangkok
}

\author{
Pantip Kayee $^{1,2}$ - Puntipar Sonthiphand ${ }^{1,2}$ - Chaiwat Rongsayamanont ${ }^{1,2}$. \\ Tawan Limpiyakorn ${ }^{1,3}$
}

Published online: 25 May 2016

(C) Springer Science+Business Media New York 2016

\section{Retraction Note to: Microb Ecol (2011) 62:776-788 \\ DOI 10.1007/s00248-011-9893-9}

This article has been retracted by the authors. At the end of 2015 , we again conducted a study at small wastewater treatment plants. Based on our recent calculation, we found that the solid retention time (SRT) values of the plants that we previously obtained and published in the article were likely not to be the operational SRT when the work was conducted. These incorrect SRT values were used in analyzing our findings; therefore, discussion about SRT can be misinterpreted. We are unable to recalculate to recheck the values during conducting the work in the past due to unavailable raw data required. Therefore we reported this to the journal to retract the article.

The online version of the original article can be found at http://dx.doi.org/ 10.1007/s00248-011-9893-9.

Tawan Limpiyakorn

tawan.1@chula.ac.th; miketawan@yahoo.com

1 National Center of Excellence for Environmental and Hazardous Waste Management, Chulalongkorn University, Bangkok, Thailand

2 International Postgraduate Programs in Environmental Management, Graduate School, Chulalongkorn University, Bangkok, Thailand

3 Department of Environmental Engineering, Faculty of Engineering, Chulalongkorn University, Phayathai Road, Pathumwan,

Bangkok 10330, Thailand 